\title{
Tingkat Self Awareness Mahasiswa Bimbingan dan Konseling Angkatan 2017 Universitas Negeri Malang Sebagai Kesiapan Menjadi Konselor Sekolah
}

\author{
Aulia Fiki Aprina, Irene Maya Simon, Djoko Budi Santoso \\ Universitas Negeri Malang, Jl. Semarang No. 5 Malang, Jawa Timur, Indonesia \\ *Penulis korespondensi, Surel: auliafiki13@gmail.com
}

Paper received: 1-4-2021; revised: 22-4-2021; accepted: 29-4-2021

\begin{abstract}
Self awareness is an individual's ability to recognize themselves and potential. Self awareness is important for guidance and counseling students to identify their own weaknesses and strengths, attitudes toward others, and manage emotions as readiness becomes school counselors. This research aims to describe the level of self-awareness of guidance and counseling students of 2017 class State University of Malang for readiness to become school counselors. The research used a quantitative approach with a survey as a data collection method. Survey research is used to gather information about self-awareness through statements. 30 percent of the population is used for trials and 70 percent is used for samples. The sampling technique is probability sampling. Data collection using a questionnaire using percentage analysis techniques. The results showed that the overall level of self-awareness was in high ( 81 percent), medium (19 percent), low ( 0 percent) categories. The level of self-awareness on the attention aspect is in high ( 99 percent), medium ( 1 percent), low ( 0 percent) categories. The level of self-awareness on the wakefulness aspect is in the high (66 percent), medium (34 percent), low ( 0 percent) category. The level of self-awareness in the architecture aspect is in high (73 percent), medium (27 percent), low ( 0 percent) categories. The level of self-awareness on the aspect of recall of knowledge is in high (84 percent), medium (16 percent), low ( 0 percent) categories. The level of self-awareness on the emotive aspect is in the high (93 percent), medium (7 percent), low ( 0 percent) category. Based on these data, it concluded that the level of self-awareness of guidance and counseling students of 2017 class State University of Malang tends to be high.
\end{abstract}

Keywords: self awareness; guidance and counseling students; school counselors

\begin{abstract}
Abstrak
Self awareness adalah kemampuan individu untuk mengenali diri dan potensi. Self awarenes penting bagi mahasiswa bimbingan dan konseling untuk mengetahui kelemahan dan kelebihan diri sendiri, sikap diri terhadap orang lain, dan kelola emosi sebagai kesiapan menjadi konselor sekolah. Penelitian bertujuan untuk mendeskripsikan tingkat self awareness mahasiswa bimbingan dan konseling angkatan 2017 Universitas Negeri Malang sebagai kesiapan menjadi konselor sekolah. Rancangan penelitian menggunakan pendekatan kuantitatif dengan survei sebagai metode pengumpulan data. Penelitian survei digunakan untuk mengumpulkan informasi terkait self awareness mahasiswa melalui daftar pernyataan. $30 \%$ dari populasi digunakan untuk uji coba dan 70 persen digunakan untuk sampel. Teknik pengambilan sampel ialah probability sampling. Pengumpulan data menggunakan angket dengan pengolahan data menggunakan teknik analisis persentase. Hasil penelitian menunjukkan tingkat self awareness secara keseluruhan dalam kategori tinggi (81 persen), sedang (19 persen), rendah ( 0 persen). Tingkat self awareness pada aspek attention dalam kategori tinggi (99 persen), sedang (1 persen), rendah (0 persen). Tingkat self awareness pada aspek wakefulness dalam kategori tinggi (66 persen), sedang (34 persen), rendah $(0 \%)$. Tingkat self awareness pada aspek architecture dalam kategori tinggi (73 persen), sedang (27 persen), rendah (0 persen). Tingkat self awareness pada aspek recall of knowledge dalam kategori tinggi (84 persen), sedang (16 persen), rendah ( 0 persen). Tingkat self awareness pada aspek emotive dalam kategori tinggi ( 93 persen), sedang ( 7 persen), rendah ( 0 persen). Berdasarkan data tersebut, disimpulkan bahwa tingkat self awareness mahasiswa bimbingan dan konseling angkatan 2017 Universitas Negeri Malang cenderung tinggi.
\end{abstract}


Kata kunci: self awareness; mahasiswa BK; konselor sekolah

\section{Pendahuluan}

Memiliki kesadaran diri berarti bahwa seseorang memiliki kesadaran yang tajam terhadap kepribadian, termasuk kekuatan dan kelemahan, pikiran dan keyakinan, emosi serta motivasi. Selain itu, dalam Duval \& Wicklund (dalam Rubens dkk, 2018) menyatakan seseorang harus melibatkan proses reflektif dalam melihat diri sendiri dari sudut pandang yang berbeda, baik bagaimana mereka melihat diri sendiri ataupun bagaimana orang lain melihatnya. Dengan demikian self awareness adalah bagaimana kemampuan seseorang dalam memahami diri sendiri dan potensinya. Semakin baik seseorang memahami diri sendiri maka semakin terampil seseorang dalam memahami orang lain.

Di sisi lain, menurut Eurich (2018) dalam penelitiannya orang-orang yang melakukan introspeksi lebih stres dan cenderung depresi, kurang puas dengan pekerjaan, hubungan mereka, dan kurang mampu mengendalikan kehidupan. Eurich mendapati 95\% orang merasa bahwa mereka sadar diri, tetapi hanya $10-15 \%$ yang benar-benar sadar. Kesimpulan yang diambil dari penelitian tersebut yakni terdapat perbedaan antara orang yang benar-benar memiliki self awareness sebagai langkah perbaikan dan orang yang merasa memiliki self awareness dengan pemahaman yang keliru.

Solso (2008) mengungkap ada 5 aspek penting dalam self awareness yang dapat membantu meningkatkan potensi diri. Terutama untuk calon konselor sekolah yang diharapkan mampu mengenal diri sendiri terkait kekuatan, kelemahan, nilai, dan pandangan hidupnya. Aspek-aspek tersebut diantaranya attention, wakefulness, architecture, recall of knowledge, dan emotive. Kurangnya kesadaran mengenai 5 aspek tersebut di beberapa indikator masih terjadi pada mahasiswa bimbingan dan konseling. Rata- rata tingkat self awareness mahasiswa program studi Bimbingan dan Konseling angkatan 2014 Universitas Sanata Dharma Yogyakarta tergolong tinggi yaitu sebesar 43,90\% namun terdapat indikator yang tergolong rendah yang harus segera diberikan program pengembangan self awarenes lebih lanjut (Hilapok, 2017).

Self awarenes dinilai penting untuk mahasiswa bimbingan dan konseling sebagai calon konselor sekolah. Self awareness yang dimiliki mahasiswa bimbingan dan konseling akan membantu mengetahui kelemahan dan kelebihan diri sendiri, bagaimana bersikap terhadap orang lain, kelola emosi, sehingga mahasiswa dapat menjadi pribadi yang matang dan siap menjadi konselor sekolah. Di samping itu, Goleman (dalam Caldwell, 2016) menjelaskan self awareness berkontribusi secara nyata dalam berurusan etis dengan orang lain. Berperilaku etis diyakini menjadi karakteristik yang diperlukan untuk meningkatkan efektivitas dalam pelayanan (Feize \& Faver, 2018). Hal tersebut membuat mahasiswa bimbingan dan konseling harus memiliki modal dasar dalam menjalankan tugas konselor yaitu dengan memiliki self awareness dalam diri (Flurentin, 2011).

Dengan demikian, peneliti melakukan penelitian dengan sasaran mahasiswa bimbingan dan konseling angkatan 2017 Universitas Negeri Malang. Diketahui beberapa di antaranya telah mengetahui secara siapa mereka, cara menempatkan diri, harapan mereka, dan bagaimana menghargai orang lain dalam kehidupan sehari-hari. Namun, ditemukan juga beberapa lainnya yang telah mengetahui siapa diri mereka, tetapi tidak ingin mencari tahu bagaimana mereka dari sisi orang 
lain. Bahkan mereka masih dapat mengabaikan kepentingannya sendiri. Berdasarkan hal tersebut, peneliti ingin mengetahui tingkat self awareness mahasiswa bimbingan dan konseling angkatan 2017 Universitas Negeri Malang sebagai kesiapan menjadi konselor sekolah.

\section{Metode}

Penelitian ini bertujuan untuk mendeskripsikan tingkat self awareness mahasiswa bimbingan dan konseling angkatan 2017 Universitas Negeri Malang sebagai kesiapan menjadi konselor sekolah. Rancangan penelitian menggunakan pendekatan kuantitatif dengan metode pengumpulan data yang digunakan adalah survei. Penelitian survei digunakan untuk mengumpulkan informasi terkait self awareness mahasiswa melalui daftar pernyataan. Keikutsertaan beberapa responden dalam penelitian survei ini diperlukan untuk memperoleh data kepercayaan, karakteristik, pendapat-pendapat, dan perilaku yang telah atau sedang terjadi (Groves, 2010).

Sampel penelitiannya yaitu mahasiswa bimbingan dan konseling angkatan 2017 Universitas Negeri Malang tingkat akhir yang dinilai telah menerima banyak materi dan bekal sebagai kesiapan menjadi calon konselor sekolah. Tidak ada ketetapan mutlak dalam penentuan besar kecilnya pengambilan sampel (Arsyad, 2001). Peneliti mengambil 70\% dari populasi sebagai sampel, sedangkan 30\% lainnya digunakan pada tahap uji coba. Pengambilan sampel dengan teknik probability sampling dengan teknik simple random sampling. Setiap sampel memiliki kesempatan yang sama untuk dipilih.

Tahap dalam penelitian survei menurut Groves (2010), ialah penyusunan angket. Setelah itu responden dengan memilih salah satu jawaban dari jawaban angket yang telah disediakan. Peneliti mengumpulkan data jawaban setelah responden mengerjakannya. Kemudian dilanjutkan dengan tahap penyortiran data. Setelah itu, peneliti memasuki proses pengelolaan data dan menyiapkannya untuk dilakukan analisis statistik deskriptif.

Dalam menganalisis hasil, peneliti menerapkan teknik analisis secara deskriptif dari teknik analisis persentase. Analisis deskriptif ini digunakan untuk mendeskripsikan sebuah data tingkat self awareness mahasiswa sehingga bisa dipahami untuk ditarik kesimpulannya. Pada tingkat selfawareness, norma kategorisasi rendah berada pada rentang $\mathrm{X}<\mathrm{M}-1 \mathrm{SD}$, sedang berada pada rentang $\mathrm{M}-1 \mathrm{SD} \leq \mathrm{X}<\mathrm{M}+1 \mathrm{SD}$, dan tinggi berada pada rentang $\mathrm{M}+1 \mathrm{SD} \leq \mathrm{X}$. Ketentuan norma tersebut akan diinterpretasikan pada tingkat self awareness secara kesulurahan, tingkat self awareness pada aspek attention, aspek wakefulness, aspek architecture, aspek recall of knowledge, dan aspek emotive.

Tabel 1. Norma Kategorisasi

\begin{tabular}{ll}
\hline Kategori & Rentang Kategori \\
\hline Rendah & $\mathrm{X}<\mathrm{M}-1 \mathrm{SD}$ \\
Sedang & $\mathrm{M}-1 \mathrm{SD} \leq \mathrm{X}<\mathrm{M}+1 \mathrm{SD}$ \\
Tinggi & $\mathrm{M}+1 \mathrm{SD} \leq \mathrm{X}$ \\
\hline
\end{tabular}

Keterangan:

$\mathrm{M}=$ Mean

$\mathrm{SD}=$ Standar deviasi

Rentang kategorisasi self awareness menurut Eurich (2018), sebagai berikut. (a) tinggi, ialah orang yang memiliki kesadaran diri (aware); (b) sedang, ialah orang yang 
selalu introspeksi diri (introspector) dan menyenangkan (pleaser); (c) rendah, ialah orang yang masih mencari jati diri (seeker).

\section{Hasil dan Pembahasan}

\subsection{Hasil}

\subsection{Deskripsi Tingkat Self Awareness}

Data yang diperoleh dalam penelitian ini adalah hasil analisis dari skala tingkat self awareness yang telah diisi oleh mahasiswa bimbingan dan konseling angkatan 2017 Universitas Negeri Malang.

Tabel. 2 Distribusi Frekuensi Kategorisasi Tingkat Self Awareness

\begin{tabular}{ccccc}
\hline No & Kategori & Klasifikasi & Frekuensi & Persentase \\
\hline 1 & Rendah & $\mathrm{X}<112$ & 0 & $0 \%$ \\
2 & Sedang & $112 \leq \mathrm{X}<168$ & 13 & $19 \%$ \\
3 & Tinggi & $168 \leq \mathrm{X}$ & 57 & $81 \%$ \\
& Jumlah & & 70 & $100 \%$ \\
\hline
\end{tabular}

Dapat diketahui bahwa sebagian besar subjek memiliki tingkat self awareness tinggi, sebesar 81\% (57 frekuensi). Sedangkan 19\% (13 frekuensi) lainnya memiliki tingkat self awareness sedang. Tidak ada satupun yang termasuk dalam kategorisasi rendah. Disimpulkan bahwa tingkat self awareness berada dalam kategori tinggi.

\subsubsection{Deskripsi Tingkat Self Awareness pada Aspek Attention}

Data yang diperoleh dalam penelitian ini adalah hasil analisis dari skala tingkat self awareness meliputi aspek attention yang telah diisi oleh mahasiswa bimbingan dan konseling angkatan 2017 Universitas Negeri Malang.

Tabel. 3 Distribusi Frekuensi Kategorisasi Tingkat Self Awareness pada Aspek Attention

\begin{tabular}{ccccc}
\hline No & Kategori & Klasifikasi & Frekuensi & Persentase \\
\hline 1 & Rendah & $\mathrm{X}<16$ & 0 & $0 \%$ \\
2 & Sedang & $16 \leq \mathrm{X}<24$ & 1 & $1 \%$ \\
3 & Tinggi & $24 \leq \mathrm{X}$ & 69 & $99 \%$ \\
& Jumlah & & 70 & $100 \%$ \\
\hline
\end{tabular}

Dapat diketahui bahwa sebagian besar subjek memiliki tingkat attention tinggi, sebesar 99\% (69 frekuensi). Sedangkan 1\% (1 frekuensi) lainnya memiliki tingkat attention sedang. Tidak ada satupun yang termasuk dalam kategorisasi rendah. Disimpulkan bahwa tingkat self awareness pada aspek attention berada dalam kategori tinggi.

\subsubsection{Deskripsi Tingkat Self Awareness pada Aspek Wakefulness}

Data yang diperoleh dalam penelitian ini adalah hasil analisis dari skala tingkat self awareness meliputi aspek wakefulness yang telah diisi oleh mahasiswa bimbingan dan konseling angkatan 2017 Universitas Negeri Malang. 
Tabel. 4 Distribusi Frekuensi Kategorisasi Tingkat Self Awareness pada Aspek Wakefulness

\begin{tabular}{ccccc}
\hline No & Kategori & Klasifikasi & Frekuensi & Persentase \\
\hline 1 & Rendah & $\mathrm{X}<16$ & 0 & $0 \%$ \\
2 & Sedang & $16 \leq \mathrm{X}<24$ & 24 & $34 \%$ \\
3 & Tinggi & $24 \leq \mathrm{X}$ & 46 & $66 \%$ \\
& Jumlah & & 70 & $100 \%$ \\
\hline
\end{tabular}

Dapat diketahui bahwa sebagian besar subjek memiliki tingkat wakefulness tinggi, sebesar 66\% (46 frekuensi). Sedangkan 34\% (24 frekuensi) lainnya memiliki tingkat wakefulness sedang. Tidak ada satupun yang termasuk dalam kategorisasi rendah. Disimpulkan bahwa tingkat self awareness pada aspek wakefulness berada dalam kategori tinggi

\subsubsection{Deskripsi Tingkat Self Awareness pada Aspek Architecture}

Data yang diperoleh dalam penelitian ini adalah hasil analisis dari skala tingkat self awareness meliputi aspek architecture yang telah diisi oleh mahasiswa bimbingan dan konseling angkatan 2017 Universitas Negeri Malang.

Tabel. 5 Distribusi Frekuensi Kategorisasi Tingkat Self Awareness pada Aspek Architecture

\begin{tabular}{ccccc}
\hline No & Kategori & Klasifikasi & Frekuensi & Persentase \\
1 & Rendah & $\mathrm{X}<16$ & 0 & $0 \%$ \\
2 & Sedang & $16 \leq \mathrm{X}<24$ & 19 & $27 \%$ \\
3 & Tinggi & $24 \leq \mathrm{X}$ & 51 & $73 \%$ \\
& Jumlah & & 70 & $100 \%$ \\
\hline
\end{tabular}

Dapat diketahui bahwa sebagian besar subjek memiliki tingkat architecture tinggi, sebesar 73\% (51 frekuensi). Sedangkan 27\% (19 frekuensi) lainnya memiliki tingkat architecture sedang. Tidak ada satupun yang termasuk dalam kategorisasi rendah. Disimpulkan bahwa tingkat self awareness pada aspek architecture berada dalam kategori tinggi.

\subsubsection{Deskripsi Tingkat Self Awareness pada Aspek Recall of Knowledge}

Data yang diperoleh dalam penelitian ini adalah hasil analisis dari skala tingkat self awareness meliputi aspek recall of knowledge yang telah diisi oleh mahasiswa bimbingan dan konseling angkatan 2017 Universitas Negeri Malang.

Tabel. 6 Distribusi Frekuensi Kategorisasi Tingkat Self Awareness pada Aspek Recall of Knowledge

\begin{tabular}{lllll}
\hline No & Kategori & Klasifikasi & Frekuensi & Persentase \\
\hline $\mathbf{1}$ & Rendah & $\mathrm{X}<40$ & 0 & $0 \%$ \\
\hline $\mathbf{2}$ & Sedang & $40 \leq \mathrm{X}<60$ & 11 & $16 \%$ \\
\hline $\mathbf{3}$ & Tinggi & $60 \leq \mathrm{X}$ & 59 & $84 \%$ \\
\hline JUMLAH & & 70 & $100 \%$ \\
\hline
\end{tabular}

Dapat diketahui bahwa sebagian besar subjek memiliki tingkat recall of knowledge tinggi, sebesar 84\% (59 frekuensi). Sedangkan 16\% (11 frekuensi) lainnya memiliki tingkat recall of knowledge sedang. Tidak ada satupun yang termasuk dalam kategorisasi rendah. 
Disimpulkan bahwa tingkat self awareness pada aspek recall of knowledge berada dalam kategori tinggi.

\subsubsection{Deskripsi Tingkat Self Awareness pada Aspek Emotive}

Data yang diperoleh dalam penelitian ini adalah hasil analisis dari skala tingkat self awareness meliputi aspek emotive yang telah diisi oleh mahasiswa bimbingan dan konseling angkatan 2017 Universitas Negeri Malang.

Tabel. 7 Distribusi Frekuensi Kategorisasi Tingkat Self Awareness pada Aspek Emotive

\begin{tabular}{ccccc}
\hline No & Kategori & Klasifikasi & Frekuensi & Persentase \\
\hline 1 & Rendah & $\mathrm{X}<24$ & 0 & $0 \%$ \\
2 & Sedang & $24 \leq \mathrm{X}<36$ & 5 & $7 \%$ \\
3 & Tinggi & $36 \leq \mathrm{X}$ & 65 & $93 \%$ \\
& Jumlah & & 70 & $100 \%$ \\
\hline
\end{tabular}

Dapat diketahui bahwa sebagian besar subjek memiliki tingkat emotive tinggi, sebesar 93\% (65 frekuensi). Sedangkan 7\% (5 frekuensi) lainnya memiliki tingkat emotive sedang. Disimpulkan bahwa tingkat self awareness pada aspek emotive berada dalam kategori tinggi.

\subsection{Pembahasan}

Berdasarkan hasil penelitian secara keseluruhan, tingkat self awareness mahasiswa bimbingan dan konseling angkatan 2017 Universitas Negeri Malang berada dalam kategori tinggi. 81\% (57 mahasiswa) memiliki tingkat self awareness kategori tinggi, sedang sebesar 19\% (13 mahasiswa), dan 0\% dalam kategori rendah. Sebagian besar dari mereka dengan self awareness tinggi. Dengan adanya self awareness, konselor dapat menunjukkan empati dengan orang lain (Richards dalam Caldwell, 2016). Selain itu, dengan self awareness konselor akan mampu membantu konseli untuk menyeimbangkan harapan yang bertolakan dengan tuntutan. Hal tersebut akan memberikan kenyamanan pada diri konseli untuk menyelesaikan persoalannya bersama konselor.

Pada hasil penelitian tingkat self awareness aspek attention, dari 70 mahasiswa bimbingan dan konseling angkatan 2017 Universitas Negeri Malang menunjukkan 99\% (69 mahasiswa) memiliki tingkat selfawareness kategori tinggi, sedang sebesar 1\% (1 mahasiswa), dan 0\% dalam kategori rendah. Menurut Preden (2015), konselor hendaknya mampu memahami keadaan sendiri dan kondisi lingkungan sekitar. Kesadaran diri yang dimaksud adalah dengan memusatkan perhatian kepada kejadian-kejadian yang ada pada dirinya sendiri maupun orang di sekitarnya. Ketika individu telah memiliki perhatian ke dalam diri terkait tindakan apa yang seharusnya diambil, maka akan terdapat proses perenungan dan pengkolaborasian pikiran-pikiran pribadi, memori-memori, dan citra visual dengan keadaan yang sedang dialaminya (Solso, 2008).

Selanjutnya, pada hasil penelitian tingkat self awareness aspek wakefulness dari 70 mahasiswa bimbingan dan konseling angkatan 2017 Universitas Negeri Malang menunjukkan 66\% (46 mahasiswa) memiliki tingkat self awareness kategori tinggi, sedang sebesar 34\% (24 mahasiswa), dan 0\% dalam kategori rendah. Berdasarkan pendapat dari Surya (2003), konselor harus mampu memahami dirinya sendiri, mengenali kelebihan, kekurangannya, kebutuhannya, dan juga kepekaan terhadap diri sendiri. Kepekaan ini menjadi sebuah 
kesiagaan individu terhadap suatu kejadian (Solso, 2008). Konselor yang memiliki siaga memiliki rencana-rencana terhadap kehidupan yang ia jalani kedepannya. Sehingga ia tidak akan mendapati kerancuan dalam menghadapi suatu hal yang tidak sesuai harapan.

Kemudian, pada hasil penelitian tingkat self awareness aspek architecture, dari 70 mahasiswa bimbingan dan konseling angkatan 2017 Universitas Negeri Malang menunjukkan 73\% (51 mahasiswa) memiliki tingkat self awareness kategori tinggi, sedang sebesar 27\% (19 mahasiswa), dan 0\% dalam kategori rendah. Diperjelas dalam Duval \& Silvia (2001), proses kesadaran diri perlu adanya pemahaman. Pemahaman diri dapat diperoleh melalui pikiran, perasaan, dan tingkah laku sesuai standar kebenaran yang ada. Self awareness akan membantu menyadari dan memahami emosi, perasaan, pikiran, dorongan hati, dan pengaruhnya dalam melakukan sesuatu untuk memahami konsep peristiwa.

Lalu, pada hasil penelitian tingkat self awareness aspek recall of knowledge dari 70 mahasiswa bimbingan dan konseling angkatan 2017 Universitas Negeri Malang menunjukkan 84\% (59 mahasiswa) memiliki tingkat self awareness kategori tinggi, sedang sebesar 16\% (11 mahasiswa), dan 0\% dalam kategori rendah. Individu yang menyadari keasliannya akan lebih terampil dalam mengelola diri ketika ia mampu memahami dengan baik jati dirinya. Keaslian atau genuine ini menjadi salah satu sifat dasar yang harus dimiliki konselor (Lubis, 2011). Termasuk ketika individu mengelola informasi yang diterima, memahami kekurangan dan kelebihannya, bertanggung jawab terhadap peristiwa-peristiwa di sekitarnya, dan mampu menyadari tindakan-tindakan orang lain terhadapnya.

Berikutnya, pada hasil penelitian tingkat self awareness aspek emotive dari 70 mahasiswa bimbingan dan konseling angkatan 2017 Universitas Negeri Malang menunjukkan 93\% (65 mahasiswa) memiliki tingkat self awareness kategori tinggi, sedang sebesar 7\% (5 mahasiswa), dan $0 \%$ dalam kategori rendah. Hal ini dikarenakan mereka memiliki self awareness yang terbentuk melalui introspeksi untuk lebih mengenali diri sendiri (Billon, 2016). Mengenali dan mengembangkan diri sendiri untuk dapat membiasakan diri memiliki karakteristik konselor yakni mampu mengatur dan mengekspresikan emosi secara stabil.

\section{Simpulan}

Berdasarkan hasil penelitian yang telah dilakukan, tingkat self awareness mahasiswa bimbingan dan konseling angkatan 2017 Universitas Negeri Malang cenderung tinggi. Hal ini menandakan adanya kesiapan mahasiswa untuk menjadi calon konselor sekolah dalam menjalankan tugasnya. Sebagian besar mahasiswa dengan self awareness tinggi, ialah orang yang memiliki kesadaran diri (aware). Sebagian kecil mahasiswa dengan self awareness sedang, ialah orang masih terbiasa untuk introspeksi diri (introspector) dan menyenangkan (pleaser). Tidak ada satupun dari mahasiswa bimbingan dan konseling angkatan 2017 Universitas Negeri Malang dengan self awareness rendah yang masih mencari jati diri (seeker).

Saran bagi bagi jurusan bimbingan dan konseling, jurusan diharapkan dapat menjadikan hasil penelitian ini menjadi sumber informasi sehingga dapat menjadi masukan bagi dosen bimbingan dan konseling untuk mampu membantu mengarahkan dan membimbing proses pengembangan self awareness mahasiswa bimbingan dan konseling Universitas Negeri Malang dalam upayanya mempersiapkan diri menjadi calon konselor sekolah. Saran bagi peneliti selanjutnya, diharapkan dapat menjadikan hasil penelitian ini menjadi bahan perbandingan dan referensi pertimbangan penelitian selanjutnya. 


\section{Daftar Rujukan}

Billon, A. (2017). Basic Self-Awareness: Lessons from the Real World. European Journal of Philosophy, 25(3), 732-763.

Caldwell, C., Hayes, L. A. (2016). Self-efficacy and self-awareness: moral insights to increased leader effectiveness. Journal of Management Development, 35(9), 1163-1173. doi:10.1108/JMD-01-20160011

Eurich, T. (2018). What self-awareness really is (and how to cultivate it). Harvard Business Review.

Feize, L., \& Faver, C. (2019). Teaching self-awareness: social work educators' endeavors and struggles. Social Work Education, 38(2), 159-176.

Fluerentin, E. (2012). Latihan Kesadaran Diri (self awareness) dan kaitannya dengan penumbuhan karakter. Jurnal Inspirasi Pendidikan, 1(1).

Groves, R. M. (2010). Survey methodology. John Wiley \& Sons.

Hilapok, M. A. (2017). Self Awareness dan Implikasinya pada Usulan Topik Program Pengembangan Diri. Skripsi. Universitas Sanata Dharma Yogyakarta: Tidak Diterbitkan.

Rubens, A., Schoenfeld, G. A., Schaffer, B. S., \& Leah, J. S. (2018). Self-awareness and leadership: Developing an individual strategic professional development plan in an MBA leadership course. The International Journal of Management Education, 16(1), 1-13.

Preden, J. S., Tammemäe, K., Jantsch, A., Leier, M., Riid, A., \& Calis, E. (2015). The benefits of self-awareness and attention in fog and mist computing. Computer, 48(7), 37-45.

Solso, R. L., Maclin, O. H., \& Maclin, M. K. (2008). Psikologi kognitif. Jakarta: Erlangga.

Silvia, P. J., \& Duval, T. S. (2001). Objective self-awareness theory: Recent progress and enduring problems. Personality and social psychology review, 5(3), 230-241. 